\title{
Emission Reduction Performance of Modified Hot Mix Asphalt Mixtures
}

\author{
Chaohui Wang, ${ }^{1}$ Qiang Li, ${ }^{2}$ Kevin C. P. Wang, ${ }^{2}$ Xiaolong Sun, ${ }^{1}$ and Xuancang Wang \\ ${ }^{1}$ School of Highway, Chang'an University, Middle-Section of Nan'er Huan Road, Xian, CN 710064, China \\ ${ }^{2}$ School of Civil and Environmental Engineering, Oklahoma State University, Stillwater, OK 74078, USA \\ Correspondence should be addressed to Qiang Li; qiang.li@okstate.edu
}

Received 8 October 2016; Accepted 14 February 2017; Published 15 March 2017

Academic Editor: Luigi Nicolais

Copyright (c) 2017 Chaohui Wang et al. This is an open access article distributed under the Creative Commons Attribution License, which permits unrestricted use, distribution, and reproduction in any medium, provided the original work is properly cited.

\begin{abstract}
Three novel asphalt modifiers with pollutant emission reduction effects and new emissions measurement equipment compatible with several preexisting asphalt production systems are developed in this paper. The effects of various modifier, asphalt binder type, and gradation of hot mix asphalt (HMA) on pollutant emissions are evaluated in the lab through a comprehensive experimental design. Furthermore, road performances are monitored to evaluate the emissions reduction of modified HMA mixture for production. With increasing modifier content, the emissions reduction performance is improved markedly, with maximum reduction of $70.5 \%$. However, the impact of modifier content on pollutant emissions reduction tends to be insignificant for dosages greater than $20 \%$ of the initial asphalt weight. Changes in asphalt type and asphalt mix gradation are found to moderately impact the emissions reduction effect. Finally, the mechanisms of emissions reduction are investigated, primarily attribute to their physical and chemical adsorption and pollutant reductive degradation characteristics.
\end{abstract}

\section{Introduction}

With the rapid development of civil infrastructure systems, industry, manufacturing, and many other sectors, environmental pollution has become one of the most serious problems in the world. Hot mix asphalt (HMA) is widely employed in the construction of road pavements due to its advantages during construction and field operation. However, HMA tends to emit large amounts of pollutant gases during both production and construction because of the high temperatures involved in these processes. These emissions not only pollute the air and exacerbate the greenhouse effect but are also harmful to the health of production and construction workers. This also violates the established targets for energy conservation and emission reduction [13]. Many existing studies have focused on reducing carbon emission during the application of HMA mixtures, including the use of warm mix asphalt (WMA), semiwarm mix asphalt (SWMA), and cold mix asphalt (CMA).

WMA releases less heat and emits less pollution during its production and application and greatly diminishes the environmental degradation associated with HMA [4-9]. The incorporation of a warm mixing agent also slows down the aging process of asphalt mixture. Shad verified that WMA develops an obvious indirect tensile strength with increased aging. Raghavendra et al. [10] conducted a comprehensive evaluation of the properties of WMA and compared a variety of these properties with the corresponding properties of HMA during asphalt production and application. Abdullah et al. [11] conducted laboratory testing to evaluate the quantity of pollutants emitted by HMA and WMA during the mixing process. They also employed a microtest method to determine the mechanism underlying the pollutant emission reductions of warm mix asphalt. Podolsky et al. [12] investigated the application of naturally occurring WMA modifiers and demonstrated that the hydrogenated glucose present in maize could reduce the mixing temperature of the asphalt mixture considerably, even to $30^{\circ} \mathrm{C}$. Currently, WMA is still in the trial stage, and the additional cost associated with the preparation of warm mixing agents has limited its wider use in some ways [13]. In addition, many doubts remain regarding whether the quality and mechanical properties of WMA mixture meet the requirements of asphalt pavement construction $[14,15]$. 
The principles underlying the production of SWMA are equivalent to those of WMA. Both employ technical methods to decrease the mixing temperature for achieving reduced pollutant emissions. The quantities of pollutants emitted by SWMA and HMA were compared by Del Carmen Rubio et al. [16] and the results showed that SWMA mixture provides for the reduced emissions of some specific pollutants at values ranging from $58 \%$ for $\mathrm{CO}_{2}$ to $99.9 \%$ for $\mathrm{SO}_{2}$. Botella et al. [17] conducted laboratory testing of a new semiwarm mix asphalt and demonstrated that the mechanical properties of the asphalt were a little different from those of HMA, indicating that semiwarm mix asphalt can perform well in actual engineering projects. While the use of semiwarm mix asphalt provides environmental benefits relative to HMA, its other road performance properties, such as stiffness, are not as good as those of HMA. Other considerations involve the additional cost associated with necessary equipment upgrading [18].

CMA has considerably lower heat requirements than either hot or warm mix asphalt and is therefore associated with a considerable reduction in pollution emissions, which offers considerable economic, social, and environmental benefits $[19,20]$. However, cold mix asphalt is used far less often than HMA. Generally, it is used in road maintenance and requires a long setting time for good road performance and stability [21]. However, the relatively poor water stability of cold mix asphalt represents a significant challenge to its wide usage [22].

As discussed above, the use of the three alternatives (WMA modifier, SWMA modifier, and CMA modifier) to HMA has relatively profound environmental benefits and helps relieve the environmental problems associated with HMA. Nonetheless, producing those asphalt materials at lower temperatures while achieving the same high level of mechanical properties and field performance remains to be a challenge. Wang et al. [7, 8, 23] conducted a comprehensive study on the influence of various types and dosages of tourmaline on the asphalt fume density, the mechanism of hot mixing on the reduction of pollutant emissions, and the road performance of tourmaline-modified asphalt. In addition, the authors conducted a comparison of the asphalt fumes derived from ordinary modified asphalt and tourmaline-modified asphalt via emissions inspection in mixing plants and trial lots. Huang et al. [24] mixed graphite into HMA, assessed its reduction in emitted fumes, and determined the underlying emission-reduction mechanism via microexperimentation. However, the optimal experimental conditions for emissions testing and the influence of the asphalt type and the grade of the asphalt mixture on the reduction in the pollutant emissions of HMA require further study.

To reduce the pollutant emissions of HMA, this study selects three basic materials with various physical and chemical adsorption characteristics and pollutant reductive degradation principles. Subsequently asphalt modifiers are developed and employed in the preparation of modified asphalt mixtures to decrease the pollutant emissions $\left(\mathrm{CO}_{x}\right.$, $\mathrm{NO}_{x}, \mathrm{HC}$, and $\mathrm{SO}_{2}$ ) during the HMA production and application process. In addition, new pollutant emission measurement equipment is developed for use with different asphalt production systems to determine the optimal experimental conditions for emissions testing. The effects of the modifier type and dosage, asphalt type, and grade of the asphalt mixture on the pollutant emissions of HMA are examined and quantified. Field performance tests are subsequently conducted to evaluate the pollutant emissions produced from the modified HMA mixtures during the process of spreading asphalt on the road surface.

\section{Raw Experimental Materials}

2.1. Selection of Raw Materials. Selection of basic materials is the first key step for the purpose of absorbing, reducing toxic substances, and reducing pollutant emission produced in the mixing and paving process of HMA. Based on physical characteristics, the chemical adsorption principle, and the reductive degradation principle, tourmaline powder, pyrite powder, and specularite powder, here denoted as T, P, and $\mathrm{S}$, respectively, are selected as basic materials to develop new asphalt modifiers, which could reduce the pollutant emission of hot mix asphalt. During the selection process, the environmentally friendly principle is taken into account. Material stability, compatibility with asphalt, production conditions, and rate of repetition of use are fully considered. The characteristics of basic materials T, P, and S are shown in Table 1.

2.2. Asphalt Mixture. AC-13 asphalt mixture is selected for testing in this paper, and the asphalt is SBS I-C modified asphalt produced in Tianjin. The three indices of asphalt (penetration, softening point, and ductility), aging performance, and relative density could meet the requirements stipulated in the Technical Specifications for Construction of Highway Asphalt Pavements (JTGF40-2004) standards. Basalt aggregate and limestone filler are local materials in Tianjin and all technical indices satisfy the demands of the Standard "Technical specification for Construction of Highway Asphalt Pavements (JTGF40-2004)." The gradation used in this paper is AC-13, and its composite gradation is shown in Table 2. The optimal asphalt-aggregate ratio in this paper is $4.88 \%$ and volume of air voids (VV) is $4.2 \%$.

\section{Testing Method}

3.1. Testing Equipment. The emission of pollutants from hot mix asphalt mainly occurs during the mixing process, which is generally conducted in mixing plants. However, most of the current studies of pollutant emission are performed through field tests [25]. However, many factors, such as open test environment, complex external influences, and poor test accuracy may result in imprecise results, which could not meet the requirements of testing and evaluation of pollutant emissions. Here, equipment for the testing of pollutant emission, as shown in Figure 1, is developed to achieve quantitative and precise elevation of pollutant emissions. The equipment consists of a sealing system, mixing system, power supply system for pollution emission transmission, test system, and waste gas treatment system. 
TABLE 1: Characteristics of basic materials.

\begin{tabular}{|c|c|c|c|c|c|c|c|c|}
\hline $\begin{array}{l}\text { Basic } \\
\text { materials }\end{array}$ & $\begin{array}{l}\text { Crystal } \\
\text { structure }\end{array}$ & Shape & Symmetry & Joint & $\begin{array}{l}\text { Relative } \\
\text { density } \\
\left(\mathrm{g} / \mathrm{cm}^{3}\right)\end{array}$ & $\begin{array}{l}\text { Emission } \\
\text { reduction } \\
\text { principle }\end{array}$ & $\begin{array}{c}\text { Compatibility } \\
\text { with asphalt }\end{array}$ & Side effect \\
\hline $\mathrm{T}$ & $\begin{array}{l}\text { Trigonal } \\
\text { crystal }\end{array}$ & Columnar & Noncentrosymmetric & No joint & $3.03-3.05$ & $\begin{array}{l}\text { Physical } \\
\text { adsorption, } \\
\text { reductive } \\
\text { degradation }\end{array}$ & Good & $\begin{array}{c}\text { No toxic } \\
\text { effect }\end{array}$ \\
\hline $\mathrm{P}$ & $\begin{array}{l}\text { Isometric } \\
\text { system }\end{array}$ & $\begin{array}{c}\text { Fine } \\
\text { disseminated }\end{array}$ & Noncentrosymmetric & $\begin{array}{c}\text { Not } \\
\text { completely }\end{array}$ & 4.9 & $\begin{array}{l}\text { Chemical } \\
\text { adsorption, } \\
\text { reductive } \\
\text { degradation }\end{array}$ & Good & $\begin{array}{l}\text { No toxic } \\
\text { effect }\end{array}$ \\
\hline S & $\begin{array}{l}\text { Trigonal } \\
\text { system }\end{array}$ & Schistose & Noncentrosymmetric & No joint & $5.0-5.3$ & $\begin{array}{l}\text { Physical } \\
\text { adsorption, } \\
\text { reductive } \\
\text { degradation }\end{array}$ & Good & $\begin{array}{l}\text { No toxic } \\
\text { effect }\end{array}$ \\
\hline
\end{tabular}

TABLE 2: Gradation composition of AC-13.

\begin{tabular}{lcccccccccc}
\hline Screen size & 16 & 13.2 & 9.5 & 4.75 & 2.36 & 1.18 & 0.6 & 0.3 & 0.15 & 0.075 \\
Passing rate (\%) & 100.0 & 94.8 & 72.3 & 48.2 & 33.5 & 23.3 & 18.0 & 14.4 & 8.7 & 6.6 \\
\hline
\end{tabular}

The sealing system is mainly used to achieve the prevention of emission of pollutants in the mixing process of the asphalt mixture. The equipment includes a sealing groove and a stirring cover. The mixing system is composed of a stirring pot and a stirring paddle, and the power system of the pollution emission transmission allows pollutant emission with a steady speed from the mixing system to the test system. The test system includes the sealing test box and HA856 gas analyzer. The purpose of establishing a waste gas treatment system is to prevent the experimental pollutants from emitting to the environment.

3.2. Performance Testing Method. The primary procedures employed in the experimental method used to assess the pollution emitted by HMA mixture are shown in Figure 2.

High-temperature stability testing is conducted at $60^{\circ} \mathrm{C}$. Asphalt concrete slabs $(30 \mathrm{~cm} \times 30 \mathrm{~cm} \times 5 \mathrm{~cm})$ are rolled repeatedly along the same track using a load wheel with a loading of $0.7 \mathrm{MPa}$, simulating the wheels of a vehicle. Before the test, the asphalt should be incubated in an oven at $60^{\circ} \mathrm{C}$ for $6 \mathrm{~h}$. The dynamic stability (DS) (i.e., the rolling times of every $1 \mathrm{~mm}$ rutting depth) is used to evaluate the high-temperature performance of the asphalt mixture.

The beam specimen for the bending test of the low temperature asphalt mixture is cut to the following specifications: $250 \mathrm{~mm} \pm 2 \mathrm{~mm}$ in length, $30 \mathrm{~mm} \pm 2 \mathrm{~mm}$ wide, and $35 \mathrm{~mm}$ $\pm 2 \mathrm{~mm}$ thick using an asphalt slab. Each group includes 4 specimens, which are placed in the incubator with $-10^{\circ} \mathrm{C}$ for more than $4 \mathrm{~h}$. The loading point is the midpoint of the specimen. The span is $200 \mathrm{~mm}$ and the experimental speed is $50 \mathrm{~mm} / \mathrm{min}$.

The residual stability of immersion Marshall test and residual strength of freezing and thawing split test are used to elevate the water stability of all asphalt mixtures. First, standard Marshal specimens are made using a Marshall compactor, and then the stability of standard specimens is assessed. Then, one group of marshal specimens is placed in water at $60^{\circ} \mathrm{C}$ for $30 \mathrm{~min}$ and the other group is remained in the water at $60^{\circ} \mathrm{C}$ for $48 \mathrm{~h}$. Finally, the stability of these specimens is tested. The specimen used in the residual strength of freezing and thawing split test is subjected to freezing and thawing split prior to obtaining the stability value.

\section{Preparation of Modifiers}

To make basic materials perform well in reducing pollutant emission, a high-energy ball mill is used to activate the potential of basic materials. After treatment with the highenergy ball mill, the specific surface area and surface energy of the three basic materials increased markedly. Moreover, the basic materials are in a nonthermodynamic stable state, and agglomeration takes place readily, which affected the performance of the materials described above. In this way, it is necessary to improve the dispersion of these three basic materials into the asphalt to prevent agglomeration and consistency problems. One or more dispersants and coupling agents are chosen for use with the three basic materials, and then the components are mixed thoroughly to make different kinds of modifiers. Finally, the best modifier would be selected after the comparison of pollutant emission reduction. The details of the preparation process are as follows.

(a) High-Energy Ball-Milling. Grind the basic material T, P, or $\mathrm{S}$ into micropowder though mechanical activation. Place the basic material $\mathrm{T}, \mathrm{P}$, or $\mathrm{S}$ into the tanks of the planetary ball mill. The selected mill ball's diameter is $10 \mathrm{~mm}$, and the 

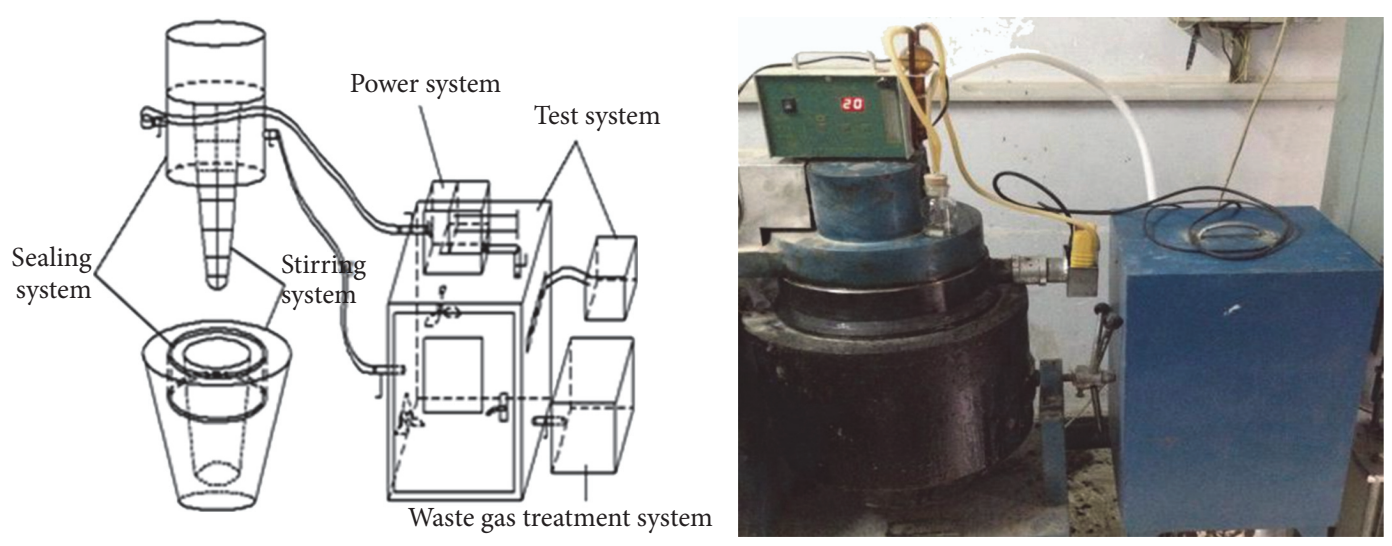

FIGURE 1: Test equipment for pollutant emission.

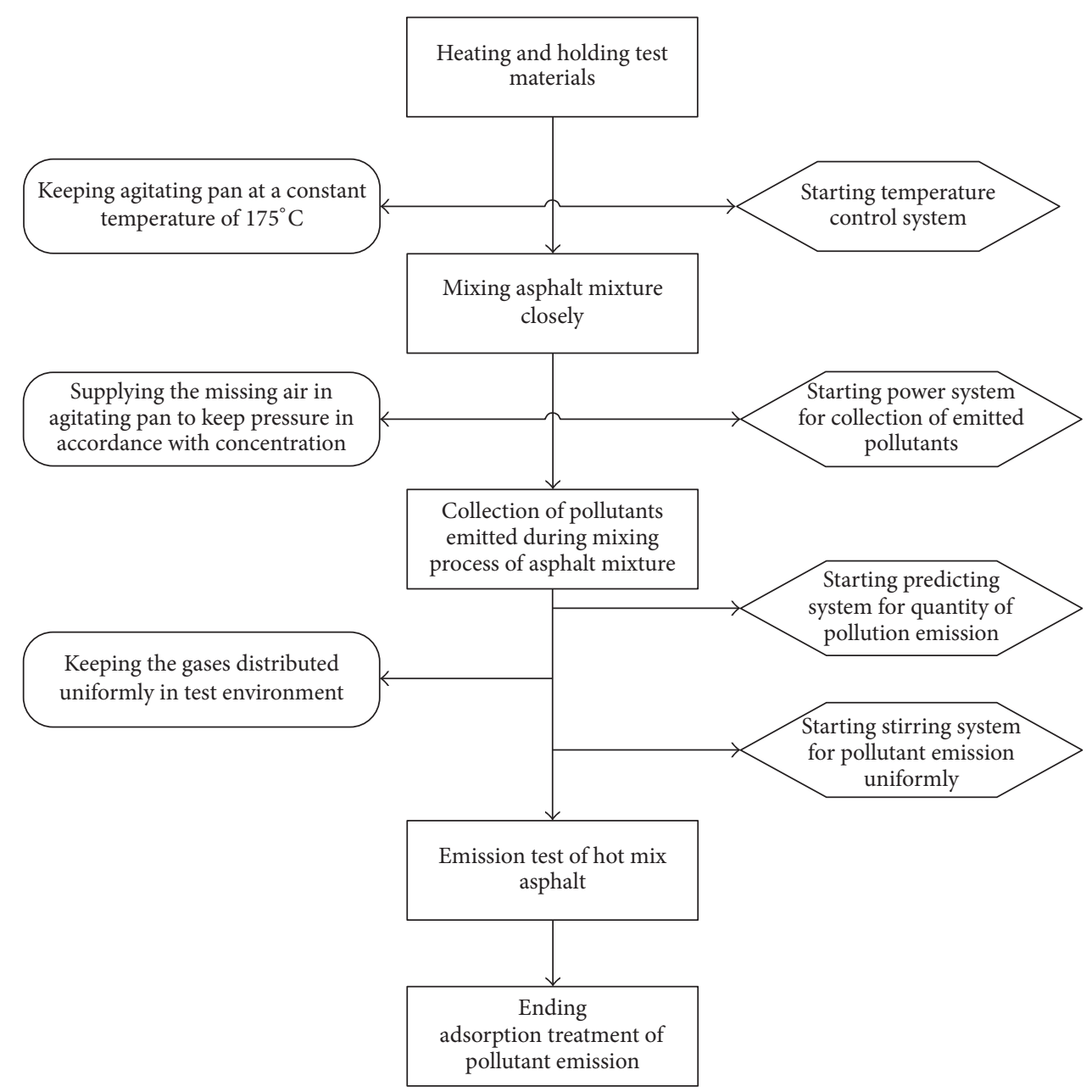

FIgURE 2: Experimental method. 
weight ratio of basic materials and ball is about $1: 20$. Then seal the tanks and wash each one for about 3-5 minutes with highly pure inert $\mathrm{N}_{2}$ gas. Finally, perform ball-milling for $30 \mathrm{~min}$. The mechanical activation can enlarge the specific surface area and increase surface activity, which will improve the emission reduction performance of basic materials.

(b) Sift the Basic Materials. Sift materials T, P, and S into separate containers to remove impurities.

(c) Dry the Basic Materials in Vacuum Oven. Place the micropowder of basic material $\mathrm{T}, \mathrm{P}$, or $\mathrm{S}$ into a vacuum oven to dry for $5 \mathrm{~h}$ at $70^{\circ} \mathrm{C}$ and degree of vacuum $93.3-98.6 \mathrm{KPa}$. This way, vacuum drying can preserve the material's original properties well, reduce the loss of quality, and maintain the material in an easily dispersed state.

(d) Choose the Optimal Dispersant for Basic Materials. Determine the optimal dispersant for T, P, and S materials. Select one or more dispersants to improve the dispersion of basic materials $\mathrm{T}, \mathrm{P}$, and $\mathrm{S}$ into asphalt. Many reactions must be enhanced to improve dispersion, such as the repulsive effect and an obvious steric hindrance effect. A dispersion medium compatible with the surface wetting properties of the micropowder must be used to ensure stable dispersion of the system. Modified asphalt is made to be used for the dispersion test using SEM analysis method. The results show the optimal dispersant for basic materials $\mathrm{T}, \mathrm{P}$, and $\mathrm{S}$ to be sodium polyphosphate and sodium hexametaphosphate at a mass ratio of $1: 2$, sodium polyacrylate, sodium hexametaphosphate, and titanate coupling agent, respectively.

(e) Combine Basic Materials to Different Recipe. Use different proportions of dried basic materials $\mathrm{T}, \mathrm{P}$, and $\mathrm{S}$ to produce $(\mathrm{TP})_{1},(\mathrm{TP})_{2},(\mathrm{TS})_{1},(\mathrm{TS})_{2},(\mathrm{PS})_{1},(\mathrm{PS})_{2},(\mathrm{TPS})_{1}$, and $(\mathrm{TPS})_{2}$ asphalt modifiers. After blending the basic materials, the compound materials can be expected to emit less pollution gas during the process of HMA mixture production because of the synergistic effect.

(f) Determine the Dispersion of Modifiers in Asphalt. Choose the optimal dispersant and compound modifiers to prepare modified asphalt and modified asphalt mixture. The SEM analysis method is used to investigate the dispersion of basic materials in asphalt. A comparison of the SEM images taken at steps (d) and (f) shows that the dispersion of different compound modifiers is similar because they are all reasonably consistent with asphalt. No layering, cohesion, or segregation is observed in the asphalt.

(g) Determine the Emission Reduction Effect of Compound Modifiers. Choose the optimal dispersants and compound modifiers to prepare modified asphalt mixtures. Then assess the emissions associated with different modified asphalt mixtures. Here, the test results showed that, compared with base asphalt, the pollutant emission of modified asphalt decreased profoundly, and modifier (TPS) ${ }_{1}$ is the most effective at reducing emissions, as indicated by the test results in step (f). The modifiers (TP) $)_{1}$ and (TPS) $)_{2}$ also have

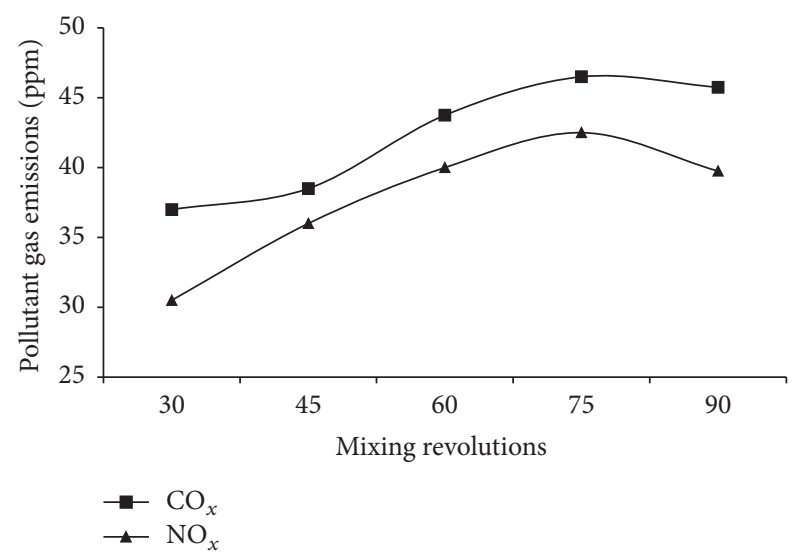

FIGURE 3: Effect of number of mixing revolutions on pollutant emissions.

better pollutant emission reduction performance than other compound modifiers, which are close to that of (TPS) ${ }_{1}$.

Regarding emission reduction as the primary reference and considering the production conditions and the cost and dispersion of modifiers, the following is determined. After mechanical activation, purity, drying, compounding, and dispersal, compound modifier (TPS) $)_{1}$ has the best comprehensive properties, followed by (TP) $)_{1}$ and (TPS) $)_{2}$. These compound modifiers are prepared to be used for further study, which are named as WEAM, WEP, and WES, respectively, in this paper.

\section{Optimal Experimental Conditions}

5.1. Mixing Revolutions. It is necessary to study the laws that govern changes in pollutant emissions from HMA mixed for different numbers of revolutions of the mixing pot. Samples mixed for $30,45,60,75$, and 90 revolutions are selected as the pollutant emission test conditions to identify the optimal mixing revolution. In particular, in this study, it was found that the modified asphalts with purifiers have decreased the amounts of $\mathrm{CO}_{x}$ and $\mathrm{NO}_{x}$ significantly. Due to the small amount of $\mathrm{SO}_{2}$ emitted in this test, the emissions of $\mathrm{NO}_{x}$ and $\mathrm{CO}_{x}$ are set as the standard indicators to confirm the influence of mixing revolutions on the emission of pollution from HMA. The tests are carried out under the conditions of $175^{\circ} \mathrm{C}$ (mixing temperature) and 12,000 g (mixture weight). The tests mainly use the SBS I-C produced in Tianjin and AC13 gradation. The results are shown in Figure 3.

As shown in Figure 3, the amount of pollution emitted increased gradually with the growth of mixing revolutions. After peaking at 75 revolutions, the amount of pollution emitted begins to decrease. This is because, during the process, asphalt is rapidly oxidized through mixing and the concentration of pollutants increases gradually until that of pollutant emitted from HMA mixture stops increasing. When the limited air runs up, the pollutant concentration peaks and begins to decrease. Considering the experimental error and accuracy, 75 is set as the optimal number of mixing revolutions for the pollutant emission testing. 


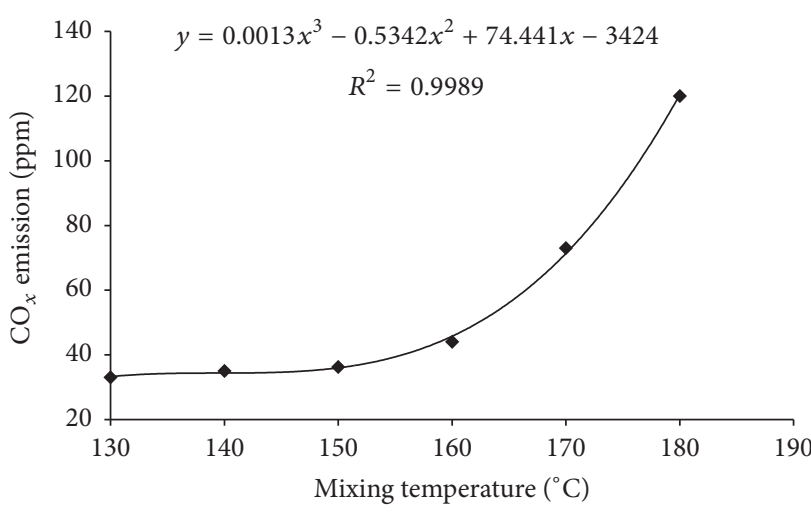

(a)

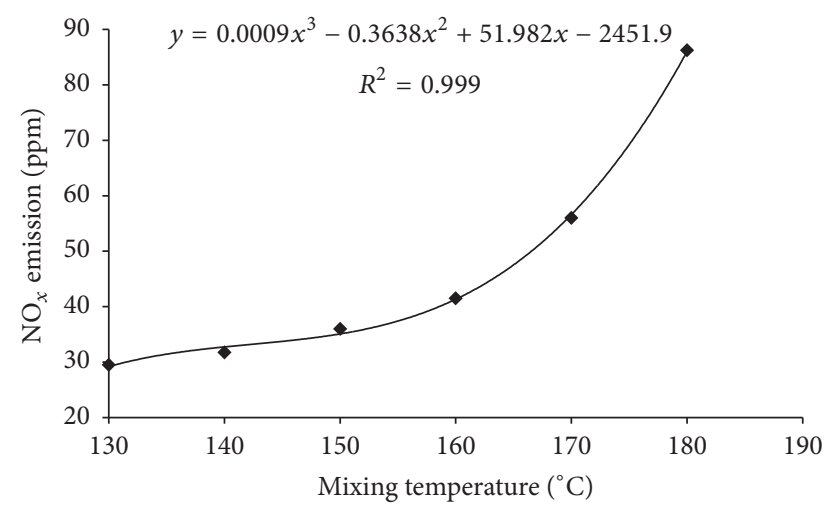

(b)

FIGURE 4: Effect of mixing temperature on pollutant emissions.

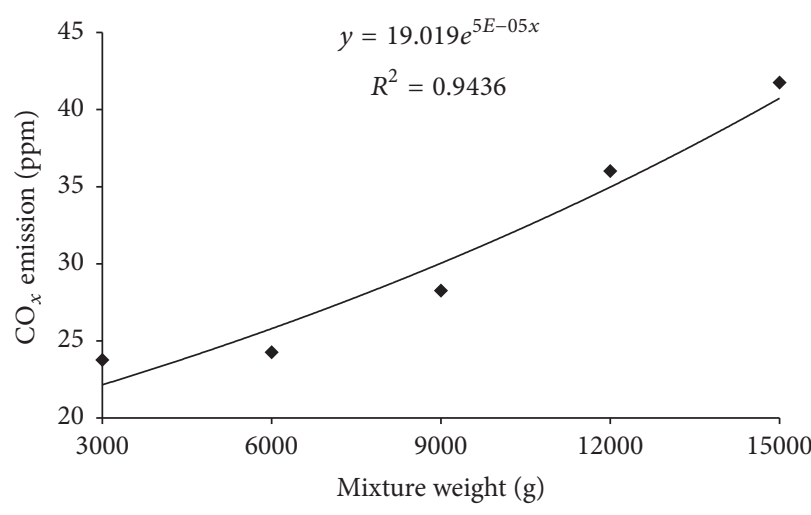

(a)

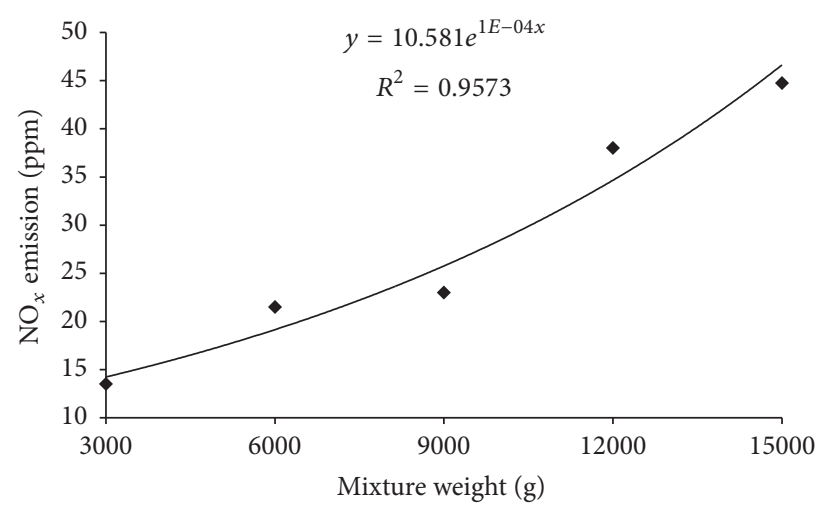

(b)

FIGURE 5: Effect of mixture weight on pollutant emissions.

5.2. Mixing Temperature. Mixing temperature is another important factor that affects the pollutant emission. $130^{\circ} \mathrm{C}$, $140^{\circ} \mathrm{C}, 150^{\circ} \mathrm{C}, 160^{\circ} \mathrm{C}, 170^{\circ} \mathrm{C}$, and $180^{\circ} \mathrm{C}$ are selected as test temperatures, in which the pollutant emissions are measured under the conditions of $12,000 \mathrm{~g}$ mixture weight and 75 mixing revolutions. The results are shown in Figure 4.

As shown in Figure 4, emissions gradually increase as mixing temperature increases. The pollutant emission and mixing temperature have a polynomial relationship, and the correlation coefficients of the regression curve are 0.9989 and 0.9990 , respectively, which means that mixing temperature is an important factor to the pollutant emission of HMA mixture. In the relevant standard, the mixing temperature of petroleum asphalt is $140-160^{\circ} \mathrm{C}$ and that of modified asphalt is $160-175^{\circ} \mathrm{C}$. In conclusion, $160^{\circ} \mathrm{C}$ is found to be the optimal mixing temperature based on the standard rules and engineering experience.

5.3. Mixture Weight. The different mixture weights are found to influence the pollutant emission because of different heated situations and the mixing degrees. Here, $3000 \mathrm{~g}, 6000 \mathrm{~g}$, $9000 \mathrm{~g}, 12,000 \mathrm{~g}$, and 15,000 $\mathrm{g}$ are selected as the test weights, in which the pollutant emission is measured at $160^{\circ} \mathrm{C}$ mixing temperature and 75 mixing revolutions. The dosages of new modifiers are $15 \%, 20 \%$, and $25 \%$ of asphalt weight and the percentage range of these three additives accounted for the weight of total mix is $0.72 \% \sim 1.63 \%$. The results are shown in Figure 5.

Figure 5 indicates that the pollutant emission increases gradually with the increase of mixture weight. The correlation between the emissions and mixture weight is readily visible, and the coefficients are 0.9436 and 0.9573 , respectively. According to experimental observations, errors can be reduced by increasing mixture weight. To avoid the limitations of equipment and material utilization, 12,000 $\mathrm{g}$ is selected as the optimal mixture weight.

These results show 75 mixing revolutions, a mixing temperature of $160^{\circ} \mathrm{C}$, and mixture weight of $12,000 \mathrm{~g}$ to be the optimal experimental conditions for measurement of pollutant emissions in the laboratory.

\section{Results and Discussions}

6.1. Impact of Modifier Types and Dosages on the Pollutant Emission. The effects of modifier types and dosages on the emission of $\mathrm{NO}_{x}$ and $\mathrm{CO}_{x}$ from asphalt mixtures are 
TABLE 3: Emission reduction rates of different types of modified asphalt.

\begin{tabular}{lccccccc}
\hline Dosage of modifier (\%) & \multicolumn{3}{c}{ WEAM modifier } & \multicolumn{3}{c}{ WES modifier } & \multicolumn{2}{c}{ WEP modifier } \\
& 15 & 20 & 25 & 15 & 20 & 25 & 20 \\
\hline Emission reduction rate (\%) & & & & & & & \\
$\mathrm{NO}_{x}$ & 39.61 & 65.93 & 69.25 & 42.11 & 65.37 & 67.04 & 63.71 \\
$\mathrm{CO}_{x}$ & 40.45 & 70.50 & 78.09 & 37.08 & 64.89 & 70.20 & 61.80 \\
\hline
\end{tabular}

Note: $\Delta Q=(Q 1-Q 2) / Q 1$

$\triangle Q$ : emission reduction rate of HMA with emission reduction modifiers;

Q1: emissions of SBS modified asphalt mixture;

Q2: emissions of WEAM/WES/WEP modified asphalt mixture.

examined using the emission reduction rate. The WEAM, WES, and WEP modifiers are used in this test. The pollutant emission test is carried out under the optimal conditions of 75 mixing revolutions, $175^{\circ} \mathrm{C}$ mixing temperature, and $12,000 \mathrm{~g}$ mixture. The average reduction rates of the tests are calculated and shown in Table 3.

The information shown in Table 3 indicates the following:

(1) The $\mathrm{NO}_{x}$ and $\mathrm{CO}_{x}$ emissions of HMA mixture decrease visibly because of the use of WEAM, WES, and WEP modifiers, with the most pronounced reduction being $78 \%$. This indicates that WEAM, WES, and WEP have good effects with respect to reducing emissions.

(2) Emission reduction becomes more pronounced at higher dosages of modifiers. As the dosage increases from $15 \%$ to $20 \%$, the emission reduction rates of $\mathrm{NO}_{x}$ and $\mathrm{CO}_{x}$ increase by $55.24 \%$ and $74.29 \%$ with WEAM and $66.45 \%$ and $75 \%$ with WES. However, when the dosages increased from $20 \%$ to $25 \%$, the reduction rates increase only slightly.

(3) There is no large difference in the emission reduction rates of $\mathrm{CO}_{x}$ among the three new modifiers when the dosage is $20 \%$. With the increase of WES or WEAM, both emissions of $\mathrm{NO}_{x}$ and $\mathrm{CO}_{x}$ show the same variation trend. However, the emission reduction performance of WEAM is better than that of WES as indicated by the general downward trend of $\mathrm{CO}_{x}$ emissions.

6.2. Binder Type and the Pollutant Emissions. The constituents of asphalt are fairly different for the types and grades of asphalt mixture. It is necessary to study the influence of different types of asphalt on the emission reduction performance of HMA by emission tests. The tests are performed on various asphalts from different production areas. The tests are carried out under the optimal conditions, in which the dosages of new modifiers are $20 \%$ of asphalt weight and the percentage range of these three additives accounted for the weight of total mix is $0.96 \% \sim 1.3 \%$. The results are shown in Table 4 .

The information presented in Table 4 indicates the following conclusions:

(1) The tests are performed using 70\# matrix asphalt from different production areas with the WEAM,
TABLE 4: Type of asphalt and emission reduction rate.

\begin{tabular}{|c|c|c|c|}
\hline \multirow[t]{2}{*}{ Asphalt type } & \multirow{2}{*}{$\begin{array}{c}\text { Modifier } \\
\text { types }\end{array}$} & \multicolumn{2}{|c|}{$\begin{array}{c}\text { Emission } \\
\text { reduction rate (\%) }\end{array}$} \\
\hline & & $\mathrm{NO}_{x}$ & $\mathrm{CO}_{x}$ \\
\hline \multirow{3}{*}{ Shandong $70 \#$ matrix asphalt } & WEAM & 65.93 & 70.50 \\
\hline & WES & 65.37 & 64.89 \\
\hline & WEP & 63.71 & 61.80 \\
\hline \multirow{3}{*}{ Shanxi 70\# matrix asphalt } & WEAM & 26.10 & 42.60 \\
\hline & WES & 73.75 & 50.00 \\
\hline & WEP & 62.37 & 39.00 \\
\hline \multirow{3}{*}{ Tianjin 70\# matrix asphalt } & WEAM & 44.06 & 31.94 \\
\hline & WES & 4.57 & 18.32 \\
\hline & WEP & 12.33 & 12.04 \\
\hline \multirow{3}{*}{ SK-70\# matrix asphalt } & WEAM & 45.41 & 45.41 \\
\hline & WES & 26.53 & 19.39 \\
\hline & WEP & 22.96 & 22.96 \\
\hline \multirow{3}{*}{ Shell 90\# matrix asphalt } & WEAM & 42.06 & 32.51 \\
\hline & WES & 27.90 & 22.17 \\
\hline & WEP & 45.06 & 33.99 \\
\hline \multirow{3}{*}{ A area SBS asphalt } & WEAM & 39.38 & 39.38 \\
\hline & WES & 15.03 & 17.10 \\
\hline & WEP & 14.50 & 21.24 \\
\hline \multirow{3}{*}{ Shanxi SBS asphalt } & WEAM & 64.42 & 63.25 \\
\hline & WES & 30.73 & 42.17 \\
\hline & WEP & 28.03 & 48.43 \\
\hline \multirow{3}{*}{ Tianjin SBS asphalt } & WEAM & 31.28 & 29.75 \\
\hline & WES & 16.11 & 18.25 \\
\hline & WEP & 35.55 & 26.75 \\
\hline \multirow{3}{*}{$50 \#$ matrix asphalt } & WEAM & 20.57 & 14.09 \\
\hline & WES & 20.83 & 19.17 \\
\hline & WEP & 11.72 & 38.45 \\
\hline \multirow{3}{*}{ 20\# hard asphalt } & WEAM & 43.94 & 42.62 \\
\hline & WES & 23.38 & 19.02 \\
\hline & WEP & 32.39 & 27.54 \\
\hline
\end{tabular}

WES, and WEP modifiers mixing into them and their emission reduction performances are found to be different. Modified asphalt from Shandong and Shanxi performs better than the others. The emission 


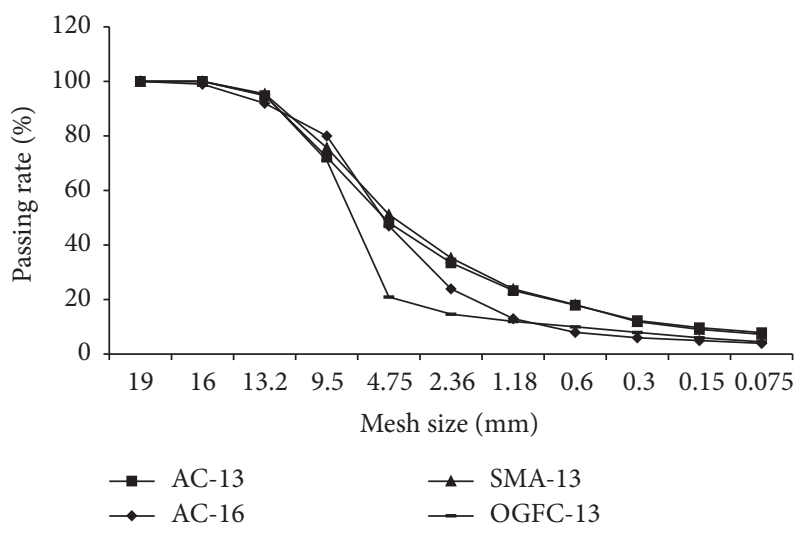

FIGURE 6: Different gradations of HMA mixture.

reduction performance of WEAM modified asphalt is the best among the three modifiers.

(2) The SBS modified asphalt produced in Shanxi Province, modified with WEAM, WES, and WEP modifiers, shows the optimal emission reduction performance. When SBS asphalt is modified by WEAM, WES, and WEP, asphalt mixture modified by WEAM shows the best performance of emission reduction.

(3) WEAM, WES, and WEP have different emission reduction effects on matrix asphalt of different labels and production areas. The WEAM and WES have poor effect on the emission reduction performance of the 50\# matrix asphalt and the 70\# matrix asphalt, respectively. The improving effect of WEP modifier on matrix asphalt does not show any obvious rules.

(4) WEAM, WES, and WEP are found to have different effects on the emission reduction performances of different asphalts. The types and production areas are also associated with differences in asphalt components. The free asphalt from the mixture is adsorbed by WEAM, WES, and WEP to varying degrees, and it caused the differences in emission reduction performance.

6.3. Impact of Mix Gradation on the Pollutant Emission. The effect of gradation types on the pollutant emission of HMA mixture is assessed in this section. The AC-13, AC-16, SMA-13, and OGFC-13 asphalt mixtures are prepared for the emission reduction test, and the optimal asphalt-aggregate ratios are $4.88 \%, 4.8 \%, 6.5 \%$, and $5.3 \%$, respectively. The composite gradations of HMA mixtures used in this section are shown in Figure 6, and the pollutant emissions of asphalt mixture of different gradations are shown in Figure 7.

AC-16 and AC-13 asphalt mixtures emit more pollutant gas than SMA-13 and OGFC-13 mixtures. The $\mathrm{NO}_{x}$ emission of AC-16 asphalt mixture is about $6.72 \%$ higher than that of the AC-13 asphalt mixture. There are no large differences in the pollutant emissions of SMA-13 and OGFC-13 asphalt mixtures. The results indicate that the pollutant emissions of HMA are affected by the composite gradations of HMA mixture to an extent.

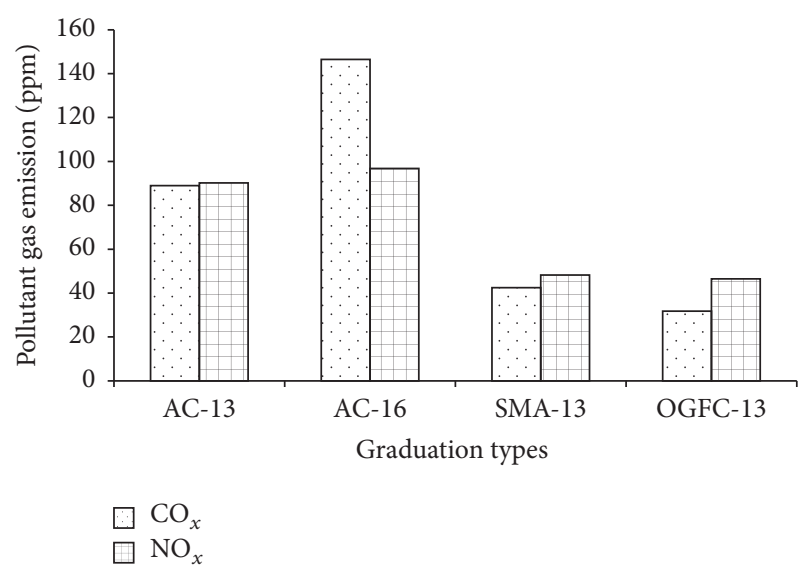

FIGURE 7: Gradation types and pollutant emissions.

Based on the four composite gradations detailed above, the HMA mixture is prepared through addition of WEAM, WES, and WEP modifiers at 20\% asphalt weight and the percentage range of these three additives accounted for the weight of total mix is $0.96 \% \sim 1.3 \%$. The results are shown in Figure 8 . The information shown in Figure 8 indicates the following:

(1) The $\mathrm{NO}_{x}$ emission reduction performance of WEAM based on the AC-13 and AC-16 asphalt mixture is obvious, but, for the SMA-13 and OGFC-13 asphalt mixtures, WEAM shows poor $\mathrm{NO}_{x}$ emission reduction performance. The pollutant reduction effect of WEAM modifier on the AC-13 asphalt mixture is $96.86 \%$ and $90.22 \%$ more pronounced than on the SMA-13 and OGFC asphalt mixtures. In conclusion, the emission reduction performance of the new modifiers is affected by various gradations.

(2) The $\mathrm{CO}_{x}$ emission reduction performance of three new modifiers on the AC-13 and AC-16 asphalt mixture is significant. However, there are static differences in terms of $\mathrm{CO}_{x}$ emission reduction effects of WEAM, WES, and WEP modifiers on the SMA-13 and OGFC-13 asphalt mixture.

(3) The different gradations show different effects on the emission reduction performance of HMA mixtures. The asphalt membrane formed on the surface of coarse and fine aggregate of different asphalt mixtures show pronounced variations in thickness. The asphalt content is affected by the dosage of mineral powder and modifier. Due to the lasting effect on the mixture with various gradations by mixing machine, the inner stress of WEAM, WES, and WEP is always changed, which leads to differences in the emission reduction performance of HMA mixture.

6.4. Field Performance. The field performance tests of different modified asphalt mixtures are evaluated in this section to assess the effects of WEAM, WES, and WEP modifiers on the road performances of HMA mixtures. The road 


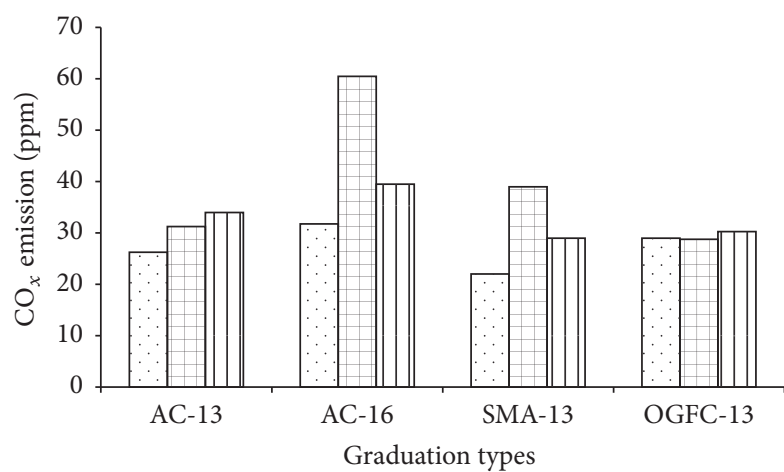

$\square$ WEAM $\square$ WES
血 WEP

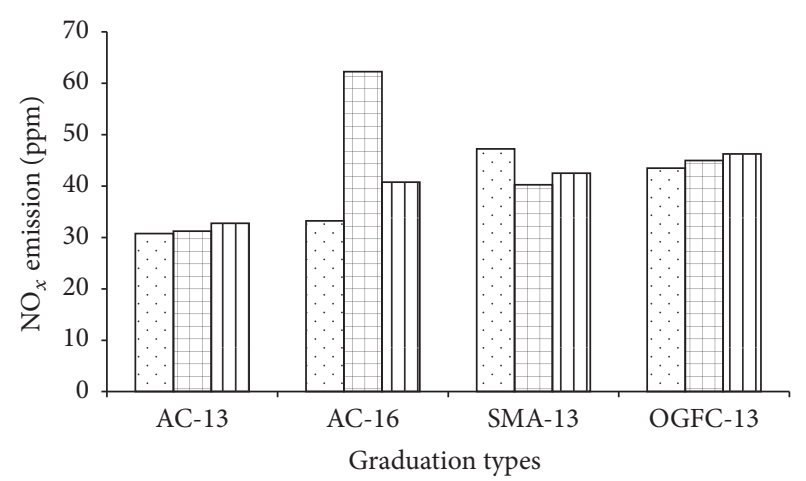

[II) WEP

(b)

FIGURE 8: Different modifiers and gradations and the emission reduction rate.

TABLE 5: Road performance and various modified asphalt mixture.

\begin{tabular}{|c|c|c|c|c|c|}
\hline Asphalt type & Dosage (\%) & Dynamic stability (times/mm) & Split-tensile strain energy $\left(\mathrm{kJ} / \mathrm{m}^{3}\right)$ & MS (\%) & TSR (\%) \\
\hline SBS & - & 8169 & $16,877.58$ & 91.07 & 87.23 \\
\hline \multirow{3}{*}{ SBS -WEAM } & 15 & 10,329 & $21,215.53$ & 92.97 & 91.32 \\
\hline & 20 & 9673 & $18,212.17$ & 96.73 & 95.86 \\
\hline & 25 & 12,708 & $18,146.04$ & 97.74 & 97.63 \\
\hline SBS -WES & 20 & 9321 & $20,165.34$ & 93.22 & 94.82 \\
\hline SBS -WEP & 20 & 9012 & $17,246.27$ & 94.00 & 94.09 \\
\hline Specification & - & $\geq 2800$ & - & $\geq 85$ & $\geq 75$ \\
\hline
\end{tabular}

performance tests use the SBS I-C produced in TianJin and AC-13 gradation. The results are shown in Table 5.

As shown in Table 5, after adding the WEAM, WES, and WEP modifiers, the dynamic stability, split-tensile strain energy, residual stability, and splitting strength of asphalt mixture are increased significantly, which mean that the hightemperature performance, low-temperature performance, and water stability of asphalt mixture are improved by the addition of emission reduction modifier. Among different road performances, the high-temperature performance and water stability of WEAM modified asphalt mixture are superior to those of other modified asphalt mixtures, and WES modified asphalt mixture shows better low-temperature performance.

\section{Mechanisms of Emission Reduction}

7.1. Adsorption Mechanism. During the mixing of asphalt mixture at high temperatures, the changes in the polarization intensity of WEAM, WEP, and WES are caused by the changes in the temperature of asphalt mixture. Then, the bound charges are not completely shielded by the original free charge, and the free charges begin to appear on the surfaces of the modifiers. The particles with positive charges and pollutant gas molecules, derived from the mixing process, are adsorbed by the free charge, which lead to sedimentation.
However, the electric field forms around the modifiers through the secondary polarization reaction, which is caused by high temperature of HMA mixture. The charged particles from the emission of asphalt mixture are attracted and repelled by the electric field, and the charged particles with low weight are adsorbed. In this way, the dust and the pollutant gas of $\mathrm{NO}_{x}$ and $\mathrm{CO}_{x}$ inside asphalt fume are adsorbed, which produce the emission reduction effect on the pollutant gas and particles. The adsorption mechanism of emission reduction is shown in the following formula:

$$
\text { dust particle }{ }^{+}+\mathrm{e} \stackrel{\text { adsorb, aggregate }}{\longrightarrow} \text { soild particle } \downarrow
$$

7.2. Degradation Mechanism. After the WEAM, WEP, and WES added to the asphalt mixture, the inner polarization effect of the modifiers is activated due to the high-activity temperature field, which form a high-strength electrostatic field around the thickness of ten microns on the surface. The high-strength electrostatic field interacts with the atmosphere electrostatic field, which could generate DC static spontaneously and continuously $[26,27]$. The DC static is capable of catalyzing and deoxidizing a part of pollutant particles into $\mathrm{CO}_{2}$ and $\mathrm{H}_{2} \mathrm{O}$. Furthermore, when the high-strength electrostatic field comes into contact with the deoxidized $\mathrm{H}_{2} \mathrm{O}$, the instantaneous discharge transferred $\mathrm{H}_{2} \mathrm{O}$ to $\mathrm{HO}^{-}$ and $\mathrm{H}^{+}$by electrolysis. Under the activating effect of the 
electric field, the negative ion will be produced by the reaction between $\mathrm{HO}^{-}, \mathrm{H}_{2} \mathrm{O}$, and acid gas molecules from the air, which would consume a large amount of pollutant gas, such as $\mathrm{CO}_{2}$ and $\mathrm{CO}$. Infrared rays released from the modifiers could activate and degrade $\mathrm{NO}_{x}$ through catalysis of the reaction between $\mathrm{NO}_{x}$ and $\mathrm{HO}^{-}$. The degradation mechanism of emission reduction is shown in the following formula.

$$
\begin{aligned}
& \mathrm{C}_{x} \mathrm{H}_{y} \mathrm{O}_{z} \frac{\mathrm{O}_{2}^{-}\left(\mathrm{H}_{2} \mathrm{O}\right)_{n} \text { disperse }}{\mathrm{O}_{2}^{-}\left(\mathrm{H}_{2} \mathrm{O}\right)_{n} \text { reduce }} \longrightarrow \mathrm{CO}_{2}+\mathrm{H}_{2} \mathrm{O} \\
& \mathrm{CO}_{2}+\mathrm{H}_{2} \mathrm{O}+\mathrm{HO}^{-} \longrightarrow \mathrm{CO}_{4}{ }^{4-}\left(\mathrm{H}_{2} \mathrm{O}\right)_{n} \\
& \mathrm{OH}^{-}+\mathrm{h}^{-}+\mathrm{NO}_{x}+\mathrm{CaCO}_{3} \frac{\text { infrared ray }}{\text { activation }} \longrightarrow \\
& \mathrm{Ca}\left(\mathrm{NO}_{3}\right)_{2} \downarrow
\end{aligned}
$$

\section{Conclusions}

In this study, three new asphalt modifiers, denoted as WEAM, WEP, and WES, are developed and added into modified asphalt mixtures to reduce pollutant emissions. The effects of modifier type and dosage, binder type, and gradation of the asphalt mixture on the pollutant emission reductions of HMA mixtures are assessed via various experimental testing methods using newly developed equipment from this study. Road performance tests are subsequently conducted to evaluate the practical effect of modified HMA mixtures during application. On this basis, the mechanisms of emission reduction are investigated. The main conclusions of this study are as follows.

(i) Three basic materials are selected based on physical and chemical adsorption properties. New asphalt modifiers, named as WEAM, WEP, and WES, are developed after mechanical activation, purity, drying, compounding, and dispersal.

(ii) A new asphalt mixing system is independently designed for the study and refitted to measure the pollutant emissions from asphalt mixtures. The optimal experimental conditions are determined for pollutant emissions measurements. The optimal number of mixing revolutions, mixing temperature, and mixture weight are $75,160^{\circ} \mathrm{C}$, and $12,000 \mathrm{~g}$, respectively.

(iii) Asphalt mixtures modified with WEAM, WES, and WEP can significantly reduce pollutant emissions relative to the unmodified asphalt. The extent of emissions reduction increases gradually with an increasing WEAM or WES dosage. When the dosage increases from $20 \%$ to $25 \%$ relative to the initial asphalt weight, both emission reductions of $\mathrm{NO}_{x}$ and $\mathrm{CO}_{x}$ tend to stabilize. It is observed that WEAM is outperforming WES in the reduction of $\mathrm{CO}_{x}$ emission.

(iv) The emission-reduction performance of HMA is affected to some extent by the asphalt binder type and mixture grade. For several particular types of binder, WEAM-modified asphalt mixtures achieve the best emission reduction performance. (v) The road performance of HMA mixtures is significantly improved when the WEAM, WES, and WEP modifiers are used. During the production and application of the HMA mixture, the inner polarization effect of WEAM, WES, and WEP is enhanced with higher temperature of the asphalt mixture, enabling the absorption and degradation of different pollutants and thus reducing the emissions of the HMA mixture.

This paper provides novel asphalt modifiers to reduce the pollutant gas emitted from the production and construction of HMA mixtures. Future work includes further study on the application method and practical application effect in real engineering projects.

\section{Conflicts of Interest}

The authors declare that they have no conflicts of interest regarding the publication of this paper.

\section{Acknowledgments}

This paper describes research activities mainly requested and sponsored by the Science and Technology projects of Ministry of Housing and Urban-Rural Development of the People's Republic of China (Program 2014-R1-019), Natural Science Basic Research Plan in Shaanxi Province of China (Program no. 2014JM2-5045), Key Scientific and Technological project in Henan Province of China (Program no. 152102210113), and Fundamental Research Funds for the Central Universities (Program no. 310821162013). That sponsorship and interest are gratefully acknowledged.

\section{References}

[1] S. Swaroopa, A. Sravani, and P. K. Jain, "Comparison of mechanistic characteristics of cold, mild warm and half warm mixes for bituminous road construction," Indian Journal of Engineering and Materials Sciences, vol. 22, no. 1, pp. 85-92, 2015.

[2] X. Peng and Z. Li, "Study on regularity of fumes emitting from asphalt," Intelligent Automation \& Soft Computing, vol. 16, no. 5, pp. 833-839, 2010.

[3] J. Zhang, E. R. Brown, P. S. Kandhal, and R. West, "An overview of fundamental and simulative performance tests for Hot Mix Asphalt," Journal of ASTM International, vol. 2, no. 5, pp. 205219, 2005.

[4] P. Q. Cui, S. P. Wu, Y. Xiao, and H. H. Zhang, "Experimental study on the reduction of fumes emissions in asphalt by different additives," Materials Research Innovations, vol. 19, pp. S1158-S1161, 2015.

[5] M. C. Rubio, G. Martínez, L. Baena, and F. Moreno, "Warm mix asphalt: an overview," Journal of Cleaner Production, vol. 24, pp. 76-84, 2012.

[6] S. Sargand, M. D. Nazzal, A. Al-Rawashdeh, and D. Powers, "Field evaluation of warm-mix asphalt technologies," Journal of Materials in Civil Engineering, vol. 24, no. 11, pp. 1343-1349, 2012.

[7] C. H. Wang, T. T. Jiang, H. He, M. Y. Hou, and X. Q. Wang, "Function of warm-mixed flame retardant OGFC asphalt mixture," Materials Review, vol. 29, no. 4, pp. 122-128, 2015. 
[8] C. Wang, P. Wang, Y. Li, and Y. Zhao, "Laboratory investigation of dynamic rheological properties of tourmaline modified bitumen," Construction and Building Materials, vol. 80, pp. 195$199,2015$.

[9] H. He, C. Wang, X. Sun, X. Wang, and X. Wang, "Preparation and road performance of new warm-mix modified asphalt," Journal of Building Materials, vol. 17, no. 5, pp. 927-932, 2014.

[10] A. Raghavendra, M. S. Medeiros, M. M. Hassan, L. N. Mohammad, and W. King, "Laboratory and construction evaluation of warm-mix asphalt," Journal of Materials in Civil Engineering, vol. 28, no. 7, 2016.

[11] M. E. Abdullah, M. R. Hainin, N. I. M. Yusoff, K. A. Zamhari, and N. Hassan, "Laboratory evaluation on the characteristics and pollutant emissions of nanoclay and chemical warm mix asphalt modified binders," Construction and Building Materials, vol. 113, pp. 488-497, 2016.

[12] J. H. Podolsky, A. Buss, R. C. Williams, and E. Cochran, "Comparative performance of bio-derived/chemical additives in warm mix asphalt at low temperature," Materials and Structures, vol. 49, no. 1, pp. 563-575, 2016.

[13] B. Prowell, G. Hurley, and E. Crews, "Field performance of warm-mix asphalt at national center for asphalt technology test track," Transportation Research Record, vol. 1998, 2007.

[14] A. Almeida-Costa and A. Benta, "Economic and environmental impact study of warm mix asphalt compared to hot mix asphalt," Journal of Cleaner Production, vol. 112, pp. 2308-2317, 2016.

[15] S. D. Capitão, L. G. Picado-Santos, and F. Martinho, "Pavement engineering materials: review on the use of warm-mix asphalt," Construction and Building Materials, vol. 36, pp. 1016-1024, 2012.

[16] M. Del Carmen Rubio, F. Moreno, M. J. Martínez-Echevarría, G. Martínez, and J. M. Vázquez, "Comparative analysis of emissions from the manufacture and use of hot and half-warm mix asphalt," Journal of Cleaner Production, vol. 41, pp. 1-6, 2013.

[17] R. Botella, F. Pérez-Jiménez, R. Miró, F. Guisado-Mateo, and A. Ramírez Rodríguez, "Characterization of half-warmmix asphalt with high rates of reclaimed asphalt pavement," Transportation Research Record: Journal of the Transportation Research Board, vol. 2575, 2016.

[18] J. C. Nicholls and D. James, "Literature review of lower temperature asphalt systems," Proceedings of Institution of Civil Engineers: Construction Materials, vol. 166, no. 5, pp. 276-285, 2013.

[19] S. Al-Busaltan, H. Al Nageim, W. Atherton, and G. Sharples, "Mechanical properties of an upgrading cold-mix asphalt using waste materials," Journal of Materials in Civil Engineering, vol. 24, no. 12, pp. 1484-1491, 2012.

[20] S. Al-Busaltan, H. Al Nageim, W. Atherton, and G. Sharples, "Green Bituminous Asphalt relevant for highway and airfield pavement," Construction and Building Materials, vol. 31, pp. 243-250, 2012.

[21] B. Gómez-Meijide, I. Pérez, and A. R. Pasandín, "Recycled construction and demolition waste in cold asphalt mixtures: evolutionary properties," Journal of Cleaner Production, vol. 112, pp. 588-598, 2016.

[22] C. Ling, A. Hanz, and H. Bahia, "Measuring moisture susceptibility of cold mix asphalt with a modified boiling test based on digital imaging," Construction and Building Materials, vol. 105, pp. 391-399, 2016.

[23] C.-H. Wang, Y.-W. Li, R. Li, Y.-Z. Zhao, and P. Wang, "Preparation of low-carbon multi-function tourmaline modified asphalt and its performance evaluation," China Journal of Highway and Transport, vol. 26, no. 5, pp. 34-41, 2013.

[24] G. Huang, Z.-Y. He, C. Zhou, and T. Huang, "Suppression mechanism of expanded graphite for asphalt fume and dynamic performance of asphalt mixture of fume suppression," China Journal of Highway and Transport, vol. 28, no. 10, pp. 1-10, 2015.

[25] A. A. Cascione, R. C. Williams, W. G. Buttlar et al., "Laboratory evaluation of field produced hot mix asphalt containing postconsumer recycled asphalt shingles and fractionated recycled asphalt pavement," Journal of the Association of Asphalt Paving Technologists, vol. 80, pp. 377-418, 2011.

[26] D. Lee, S. H. Baek, T. H. Kim et al., "Polarity control of carrier injection at ferroelectric/metal interfaces for electrically switchable diode and photovoltaic effects," Physical Review BCondensed Matter and Materials Physics, vol. 84, no. 12, Article ID 125305, 2011.

[27] I. Akihiro and K. Kay, "Pyroelectric effect and possible ferroelectric transition of helimagnetic," Journal of Physics: Condensed Matter, vol. 8, no. 15, pp. 2673-2678, 1996. 

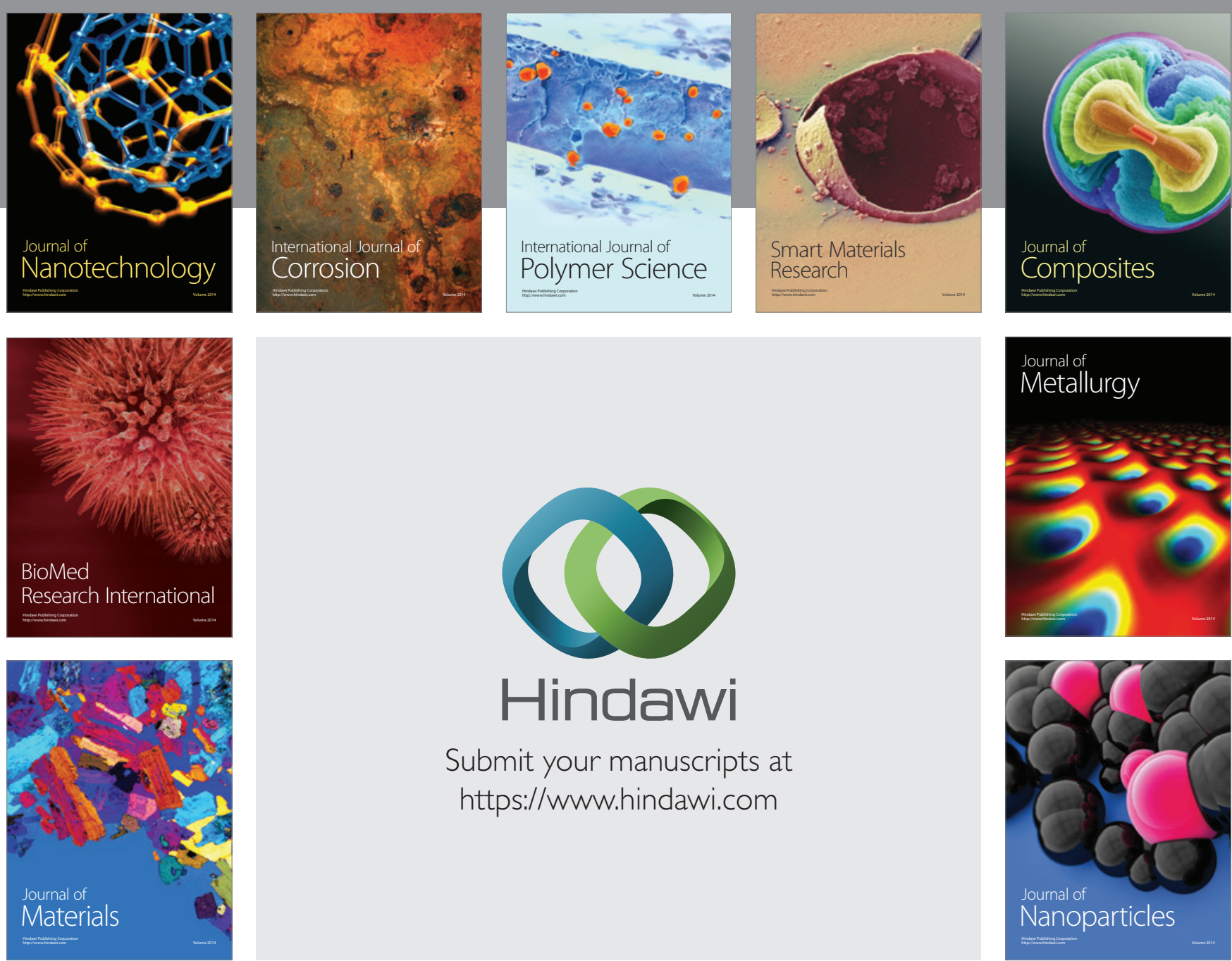

\section{Hindawi}

Submit your manuscripts at

https://www.hindawi.com

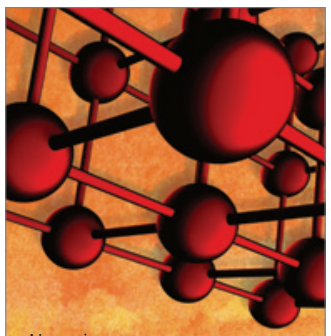

Materials Science and Engineering
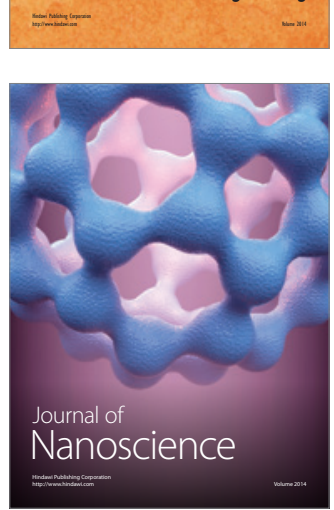
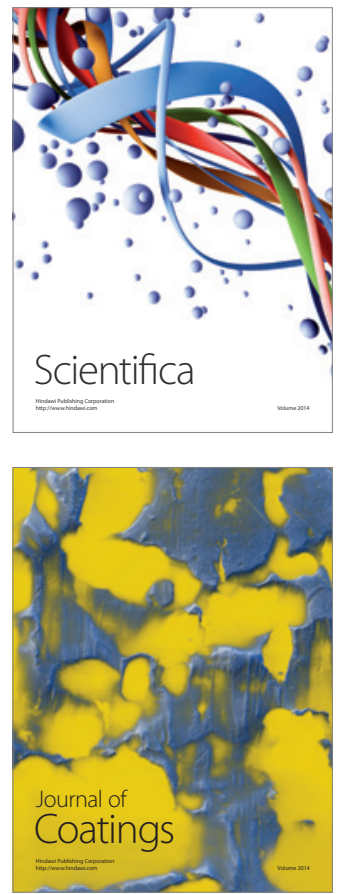
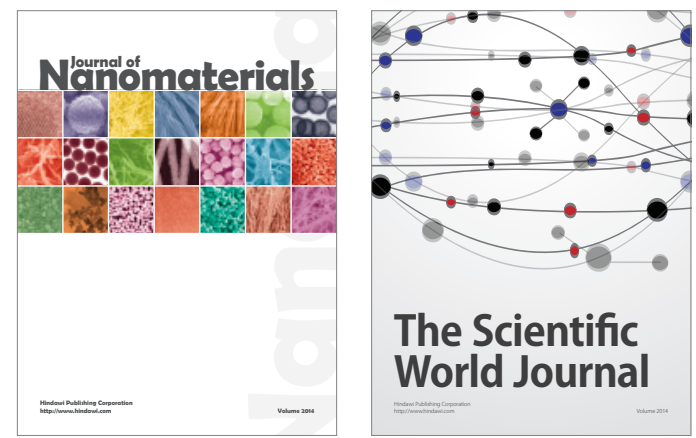

The Scientific World Journal
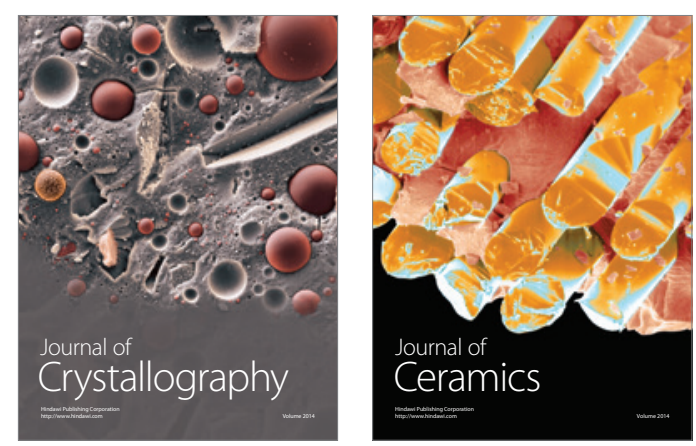
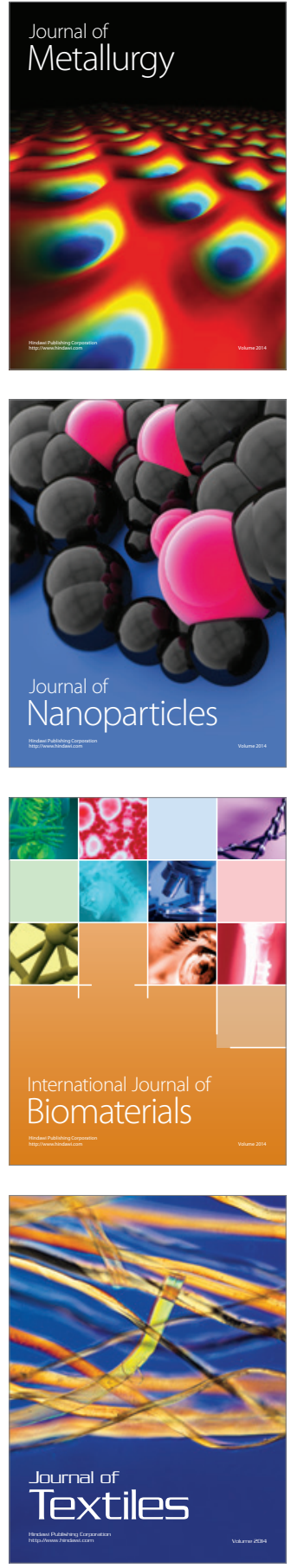